\title{
Agenda-setting and Public Policy in Private Foundations
}

\author{
${ }^{1}$ QUT Business School, Queensland University of Technology - QUT, Brisbane, Queensland 4001, Aus- \\ tralia, E-mail: a3.williamson@qut.edu.au, b.luke@qut.edu.au. https://orcid.org/0000-0002-2462-709X, \\ https://orcid.org/0000-0003-3077-662X.
}

\begin{abstract}
:
This paper examines advocacy, agenda-setting and the public policy focus of private philanthropic foundations in Australia. While concerns have been raised regarding advocacy and public policy influence of foundations in countries such as the U.S., less is understood on this issue in other contexts. Interviews were conducted with 11 managers and trustees of 10 Private Ancillary Funds (PAFs) in late 2014. Analysis of publicly available data on the participating PAFs was then undertaken comparing PAF information available at the time of the interviews with that available approximately five years later, to consider any changes in the public communication of their agendas. Findings reveal PAFs' agendas were largely consistent with public policy but may vary in the approaches to address social causes. Further, a preference for privacy indicates the PAF sector may be characterised as 'quiet philanthropy' rather than having a visible public presence. As such, PAFs' advocacy focused on promoting philanthropy, rather than altering or influencing public policy. Our main contention is that the conceptions of advocacy in structured philanthropy are dominated by the obvious, the outliers and the noisy. Our contribution to the philanthropic literature is a more nuanced and broader discussion of how advocacy and agenda-setting occurs and is understood in the mainstream.
\end{abstract}

Keywords: private philanthropic foundations, family foundations, agenda-setting, advocacy, public policy, public benefit, Australia

DOI: $10.1515 / \mathrm{npf}-2019-0049$

\section{Introduction}

This paper examines advocacy, agenda-setting and the public policy influence of Private Ancillary Funds (PAFs), foundations established by a close donor group, typically a couple or family group. Foundations have potential power and influence beyond their grantmaking, and the advocacy and influence of foundations in countries such as the U.S. have been criticized (Callahan 2017, Reich 2018, any others). However, this influence is often not exercised in an Australian context, where many foundations are considered to be traditional and cautious (McGregor-Lowndes and Williamson 2018) and rarely actively engage in advocacy or agenda-setting.

Modern foundations are often perceived as an American invention (Anheier and Toepler 1999), risking undervaluing the wide variety of foundation types in other countries. "Foundations may assume different forms and play different roles in European countries or Australia and Canada than in the United States" (Anheier and Daly 2006, 6). Hence, the very public profile of select foundations involved in advocacy risks misrepresenting a sector which may pursue a variety of activities, advocacy not necessarily being one. The concept and practice of foundations as potential private agenda-setters in a public domain is under-researched, particularly in an Australian context. Accordingly, this study's aim is to examine the activities of $10 \mathrm{PAFs}$ through semi-structured interviews. Rare access to this very private group provides key insights into the perspectives of PAF managers and trustees and their perceptions around PAF involvement in public policy, agenda-setting and advocacy. Examination of publicly available data on these PAFs was subsequently undertaken, comparing data available at the time of the interviews with that available approximately five years later, to consider potential changes in these PAFs' public communication of their position and activities regarding public policy, agenda-setting and advocacy.

Recent U.S. discourses around the undemocratic influence of extremely wealthy U.S. philanthropists are less relevant in other national contexts (Acs 2013; Fack and Landais 2012) including Australia. In the context of a Western, Anglophone democracy, findings from this study portray a different picture, presenting preliminary

Alexandra Kate Williamson is the corresponding author

(c) BY (c) 2020 Williamson and Luke, published by De Gruyter.

This work is licensed under the Creative Commons Attribution 4.o Public License. 
evidence to inform and spark international discourses about the advocacy and agenda-setting of the broader 'middle-ground' of philanthropic foundations.

Jung and Harrow (2015) refer to polarized debates about philanthropy that reject the middle-ground and "draw academic, policy and practice gazes away" from the "history and diversity of philanthropy's achievements" (Jung and Harrow 2015, 48). Our main contention is that the conceptions of advocacy in structured philanthropy are dominated by the obvious, the outliers and the noisy. Our contribution to the philanthropic literature is a more nuanced and broader discussion of how advocacy and agenda-setting occurs and is understood in the mainstream.

\section{Research Context}

Ancillary funds are charitable trusts established by deed for the purpose of making grants for public benefit ${ }^{1}$ in Australia. They may not operate programs or deliver services, but instead play a supporting role through funding eligible nonprofit organisations. There are two types of ancillary funds, private and public, with PAFs resembling modified U.S.-style family foundations (McGregor-Lowndes and Crittall 2015). Ancillary funds are regulated by legislated Australian Treasury guidelines, updated in 2019, as well as by the Australian Taxation Office (ATO) and the national charities regulator, the Australian Charities and Not-for-profits Commission (Murray 2019; Ward 2016).

Often established as family foundations, PAFs are funded by a small, tightly-bound donor group (e.g. an individual, couple, family or corporate) and may not accept public donations. PAFs must have a corporation as a trustee, rather than individual persons. A PAF must distribute at least $5 \%$ of the market value of its net assets as at the end of the previous financial year. They are an attractive philanthropic structure to living philanthropists, often those who have earned their wealth through a successful professional career, entrepreneurial business, and/or some level of inheritance. PAFs which engage in funding for advocacy and policy change may be driven by their (often living) founder(s)' interests (McLeod 2013).

PAFs are a relatively new giving structure, established in 2000-2001 to grow philanthropy in Australia. This goal is being achieved, with strong and ongoing growth in PAF numbers ( $n=1,782$ in June 2019) making them a high-profile part of the philanthropic sector (McLeod 2018). The most recent data from the ATO on PAFs' combined capital value and distributions are for the 2016-17 financial year and show an aggregated value of AU\$9.391 billion and distributions of AU\$451 million (Australian Taxation Office 2019). PAFs may only make grants to certain groups of nonprofit organisations that are endorsed by the ATO as Deductible Gift Recipients. There are no specific constraints on agenda-setting and advocacy by PAFs beyond those applying to all Australian charities (e. g. activities compromising public safety or national security).

Prior to 2010, opposition to advocacy by philanthropic foundations came from regulatory bodies, principally the ATO, rather than from a politically led, legislative inquiry. Foundations' timidity therefore arose from fear of sanctions, rather than from public censure or disapprobation. In 2010 the ATO brought the prominent Aid/Watch case before the High Court of Australia (Aid/Watch Incorporated v Commissioner of Taxation 2010) where advocacy was tested as a legal activity for charities including foundations (O'Halloran and McGregor-Lowndes 2011). The ruling in favour of Aid/Watch opened the door for charities to engage in and for foundations to fund advocacy, allowing "more room for campaigning and advocacy activities for charities generally" (Lee 2015, 277). The legacy of the case is "a comparatively liberal advocacy regime for charities compared with other common law jurisdictions" (McGregor-Lowndes and Williamson 2018, 1762). While the ruling resulted in some foundations becoming much more active in the policy space, the legacy of caution and narrow interpretation endures (Seibert 2019), perhaps while or until there is turnover in foundations' trustees.

Subsequent to the Aid/Watch case, in 2013 the charitable purpose of advancing public debate was established in Section 12(1)(1) of the Australian Commonwealth Charities Act (Commonwealth of Australia 2013). It states that charitable purpose includes promoting or opposing a change to any matter established by law, policy or practice where the change relates to any other charitable purpose listed in the Act. Such changes can be in any Australian jurisdiction, or in another country (Commonwealth of Australia 2013).

Disqualifying purposes (Division 3 of the Act) include activities that are unlawful or contrary to public policy (defined as the rule of law, the constitutional system of government of the Commonwealth, the safety of the general public and national security), or promoting or opposing a political party or a candidate for political office. However this disqualifying purpose "does not include distributing information, or advancing debate, about the policies of political parties or candidates for political office (such as by assessing, critiquing, comparing or ranking those policies)" (Commonwealth of Australia 2013,11). It is also noted in the Act that "activities are not contrary to public policy merely because they are contrary to government policy" (Commonwealth of Australia 2013, 11). 
Many Australian foundations remain cautious about engaging at a policy level, and influence on public policy is an active goal of a very small number of Australian foundations (Baker, Barraket, and Elmes 2017). Law, advocacy and politics were included by only $8.8 \%$ of respondents to the Giving Australia survey of philanthropists (individual donors and/or foundation managers or trustees) (Baker, Barraket, and Elmes 2017) as an issue or area to which most of their funding was allocated (multiple choices were possible). This category included civic, advocacy, legal and policy organisations, and was ranked equal eighth with two other issues ('philanthropic intermediaries', and 'other'). This compares with a figure of $13 \%$ for the largest U.S. foundations (Gibson and Bokoff 2020) and just $1 \%$ for the largest Canadian foundations (Philanthropic Foundations Canada 2017).

There is an ongoing conservative political narrative against charity advocacy, especially by environmental charities including some foundations (McGregor-Lowndes 2018). "The environmental foundations' path in a country with significant fossil fuel export production and environmental treasures such as the Great Barrier Reef may present an intriguing longitudinal case study of those that choose to protect the environment by direct remediation, and those that engage at the political policy level" (McGregor-Lowndes and Williamson 2018, 1775).

Further, philanthropy in Australia may be met with caution rather than celebration (Leat 2004; Williamson, Luke, and Furneaux 2019a), given Australia's culture of egalitarianism combined with the heritage of an English reserved stance on discussing giving in public. While this may inadvertently create "an undervaluing of homegrown generosity and philanthropy" (Scaife et al. 2015, 494) it preserves a sense of privacy that many PAFs value (Williamson et al. 2017). This is slowly changing as a small number of private donors publicly make significant gifts, perhaps influenced by the international scope of the 'Giving Pledge' (Scaife 2013; Seibert 2017). Yet the philanthropic activities of the ultra-wealthy in Australia (e. g. Ramsay, Forrest, Potter, Lowy, Tuckwell, Ainsworth, Kinghorn, Wakil, Gandel, and Pratt, the top ten largest private foundation or individual givers in 2017-18)(Coates 2019) have attracted comparatively little comment or censure. ${ }^{2}$

Australian foundations have traditionally funded ameliorative work rather than policy and/or structural change (McGregor-Lowndes and Williamson 2018) or to adopt a metaphor, funded the ambulance at bottom of the cliff, rather than the fence at the top. Many foundations continue to subscribe to the idea that providing funding or "risk capital" to nonprofit organisations for short-term pilot projects will lead to policy change, believing that if a project is shown to work, then governments will value the evidence and step in with largescale, ongoing funding. Foundations' work is described as characteristically " ... indirect, facilitative, advocacy through funding other organizations or projects" (Jung, Kaufmann, and Harrow 2013, 37). This is echoed in an Australian context "The Holy Grail aspired to by many professional foundation staff is to have innovation that is measured as successful, then followed by the state fully funding the initiative. In most cases, this grail is elusive" (McGregor-Lowndes and Williamson 2018, 1767). This view of foundation advocacy is decried as naïve "Blinded by our own optimism, we failed to account for a larger reality: We were trying to reform huge, complex, entrenched, multibillion-dollar public systems" (Bailin, quoted in Franklin 2014, 230).

For foundations, an alternative to grantmaking for service provision is a focus on changing public policy through public information campaigns and advocacy work with the expectation of seeing change happen through politics and policy (Frumkin 2004).

Charity moves millions but advocacy can move billions. If you spend all your money on doing some social good in the community that's great but if you can shift government policy that will release billions in the current budget and the one after that and the one after that - it changes the parameters. You end up shifting a lot more money than what you could supply in the first place. (Sue McKinnon, McKinnon Foundation, quoted in Joyce (2016)).

Thus, foundations may fund charities to undertake policy advocacy through activities including research and dissemination, raising awareness, community organising, grassroots mobilisation, building capacity, policy development, lobbying, and litigation (Seibert 2018). A recent report on advocacy in Australian philanthropy (Seibert 2018) includes brief case studies, however the focus is on the causes or issues funded rather than on the foundations themselves. In three of the eight cases, agenda-setting activities beyond direct funding are identified. These activities are establishing a nonprofit organisation in response a niche need; leveraging funding from other philanthropic donors; recognising and tapping into the expertise of peak bodies; and planning long-term strategies supporting a cause.

\section{Literature Review}

There is a conflict for private foundations between their privateness and their engagement with public policy (Williamson, Luke, and Furneaux 2019b). The terms advocacy, agenda-setting and framing are all used in the 
literature to explore and explain foundations' endeavours to influence public opinion and public policy. In this paper, however, we focus on the concepts of agenda-setting and framing as working to change the ways in which a particular issue of interest and concern to a foundation is understood. Understandings of concepts such as 'philanthropy' and 'nonprofit sector' and how the relationships between them are framed affect the study of these phenomena (Muukkonen 2009; Daly 2012).

Foundations can " ... buy talent, promote causes, and, in effect, establish an agenda of what merits society's attention" (Arnove 1982, 1). Foundations can fund survey research and advocacy organisations, publish and promote reports, convene meetings and symposia, and hence help to elevate issues to broad public concern (Weissert and Knott 1995). Private family foundations such as PAFs add value to public management through their roles in "grantmaking; advancing social innovation; field-building; shaping ideas; and advocating for policy and social change" (Phillips 2018, 151). Agenda-setting or putting items on a public agenda is the first stage of the policy process. Open or opening policy windows can also catalyse philanthropy and create valuable opportunities for particular causes to be addressed (Kingdon and Thurber 1984). Suárez (2012) finds that foundations that are younger and smaller are more likely to engage in grantmaking as a form of advocacy for social justice.

While some foundations have a deliberate agenda-setting motive and may be strongly partisan in their work, other foundations with no active intention to influence public policy may nevertheless achieve accidental, incidental, or tangential influence on a smaller scale (Anheier and Leat 2018). Advocacy may not target policy change but may focus on implementation and direct reform such as through litigation and public education (Gen and Wright 2018). A dictionary definition describes advocacy as active support of a cause or course of action (Advocacy n.d.). However, the term 'advocacy' can be used in the sense of recommendation (endorsement, promotion, justification, championing), backing (sanction, approval, patronage), encouragement (support, boost, stimulation), and espousal (defence, adoption, maintenance), and suggests that if foundations remain cautious about using the term 'advocacy', they may be using different words to capture the same activity.

\subsection{Framing and Agenda-setting}

Framing theory (Goffman 1974) is linked with agenda-setting and is understood as limiting and focusing attention, thereby enhancing perceptions. "Frames are principles of selection, emphasis and presentation composed of little tacit theories about what exists, what happens, and what matters" (Gitlin 1980, 6). In a policy sense, framing is the process through which individuals, organisations and groups legitimise certain ways of acting, and delegitimise other ways (Goffman 1974). Such links between framing, power and control make the concept of framing helpful for examining how people use their own interpretations to shape others' meaning-making and agenda-setting processes (Mills 2011). Franklin (2014) provides " ... examples of foundations exerting influence on the field and on their grantees by crafting, funding or directly running communications and public relation campaigns designed to frame policy issues according to their beliefs and strategies" (Franklin 2014, 163). An example of framing in a philanthropic context is offered by (Nisbet 2018) around climate change philanthropy in the U.S., noting foundations played a role in framing climate change as 'a pollution problem' solvable by market strategies. Philanthropic funding supported "insider" groups seeking policy action by way of negotiation, coalition building, and compromise, rather than grassroots "outsider" groups (Nisbet 2018).

Agenda-setting theory (McCombs and Shaw 1972) purports that media can set the public agenda by providing the public with topics/issues to think about. Agenda-setting theory is thus a very broad-based communication theory used to study the impact of news media on setting the public agenda and forming public opinion on selected issues by creating public awareness and concern. Kingdon and Thurber (1984) explore agenda-setting theory with regard to public policy, considering the mechanisms through which issues become part of the policy agenda. They examine how subjects become issues for legislators, asking how, why and when subjects come to regulators' attention in a public policymaking context. As agenda-setting theory has developed, recent research on U.S. charities proposes that agenda-setting theory can influence how the public thinks about issues/topics by focusing on specific, negative details in reporting (Jones, Cantrell, and Lindsey 2019).

Rogers and Dearing (1988) identify three types of agenda-setting: public agenda-setting, media agendasetting (or 'agenda building'), and policy or political agenda-setting, in which elite policymakers' agendas are targeted. For philanthropic foundations, while the first two types are possible, policy or political agenda-setting is the most likely, as philanthropists work with and influence their elite peers.

The position of foundations' trustees on agenda-setting is critical in determining the advocacy and policy stance of a foundation. Trustees can use their voice for policy agendas by publicly stating their support and working to build broad alignment. Trustees often have privilege and connections, which enable them to talk with other people of privilege and say things that foundation and nonprofit staff may not. For trustees, focusing on grantmaking rather than agenda-setting potentially represents a dissipation of their power and influence 
on matters foundation staff could manage directly and more effectively. The trustees' role, perspective and approach is an important determinant of grantmaking decisions, personal engagement, and a foundation's role and identity (Irvin and Kavvas 2019), yet is under-examined.

Silber (2012) discusses civic anger directed against the state or politics as a motivation for greater engagement in advocacy philanthropy, calling for "further comparative exploration of the varying moral and emotional tenor of elite philanthropy as an expanding mode of public action in contemporary civil societies" (Silber 2012,320). Some Australian foundations may be politically engaged and actively seek to influence and support broad policy agendas, although they are comparatively rare (Baker, Barraket, and Elmes 2017). Australian foundations "are also far less likely than their counterparts in the United States to be actively involved in influencing public policy" (McGregor-Lowndes and Williamson 2018, 1762). Influence may be achieved indirectly through the establishment and/or funding of (nominally) independent political and advocacy beneficiaries. A direct comparison with the U.S. around philanthropy and advocacy reflects on an Australian environment of caution where advocacy is not expected practice.

... most interesting to me ... was the way in which the American foundations don't find the idea of doing work on policy and advocacy - it's not at all a problem for them. It's absolutely bread and butter for them - where here [in Australia] you sort of feel like you have to be very circumspect about even using the word advocacy (Scaife et al. 2012, 113).

\subsection{Philanthropic Foundation Advocacy in Australia}

The distinction between advocacy solely through funding, versus advocacy plus funding, is echoed in more recent discussions in Australia around philanthropy and systems change internationally. Agenda-setting and policy advocacy are noted as requiring internal change within foundations regarding how they provided support, such as providing larger and longer-term grants (Curtis, Vanstone, and Weinstein 2019). However, these activities and approaches describe foundations funding advocacy work undertaken by beneficiaries, rather than agenda-setting by foundations themselves. This distinction between funding advocacy and engaging in advocacy is also blurred by Roelofs (2015) who states in a U.S. context that "Foundations' power is exerted in many ways, such as by funding progressive organisations and movements; sponsoring policy "think tanks" and organisations of public officials; influencing the political culture through media, academic researchers, and university programs ... and co-opting activists and potential rebels among the rich and poor" (Roelofs $2015,654)$. Similarly, functions and roles of private foundations in relation to public management may include both approaches: "grantmaking; advancing social innovation; field-building; shaping ideas; and advocating for policy and social change" (Phillips 2018, 151).

Foundation staff and trustees may choose to give beyond money, donating "time, experience, and/or voice to grant recipients and bodies that promote grantees' interests. This help varies from advocacy to find further funding, to volunteering, and connecting nonprofits with helpful networks" (Scaife et al. 2012, vi). These approaches to engagement beyond grantmaking "seem to find wide acceptance as a legitimate and complementary part of the role of a philanthropic trust or foundation" (Scaife et al. 2012, 113).

The unintentional nature of some Australian foundations' engagement in advocacy work is highlighted in a study by Scaife et al. (2012) "We've actually found ourselves as a bit of [an] advocacy agency, not that we ever thought - we didn't start out doing that. But in many ways, we've ended up doing some of that work" (Scaife et al. 2012, 113). This comment also highlights the elapsed time before many foundations identify the approaches that best fit their mission and purpose, noted in the literature as the dominant pattern for foundations (Graddy and Morgan 2006; Lungeanu and Ward 2012; Nemon et al. 2015).

Other concerns noted by Scaife et al. (2012) around advocacy were reputational damage, negative media, and unwillingness to directly challenge government policy. Nuanced views were reported about engagement between the philanthropic sector as a whole and government policy, including the interplay between private and public funding. Philanthropic funding could be seen as supporting government policy agendas or addressing / underscoring gaps in those agendas. "I think a lot of philanthropists, particularly if they're business people, like to counterbalance what they see the government doing, either that they agree or disagree with ... so I think there's a really interesting nexus between public policy and philanthropy" (Scaife et al. 2012, 114). Philanthropic giving was perceived "... to add some flexibility and innovation in what we do, rather than being dictated by government cycles, changes in policy, changes in leadership, short-term agendas" (Baker, Barraket, and Elmes 2017, 39). 


\section{Methods}

This study adopts an exploratory, qualitative approach. Semi-structured, in-person interviews of approximately one hour's duration were undertaken with 11 managers and trustees from 10 PAFs across three Australian states in late 2014. The PAFs recruited for the study were not chosen using (high) engagement with advocacy as a criterion, but rather for a diverse purposive sample based on size, age and state location. The sample thus provides a range of perspectives regarding whether, and if so how, PAFs engage in advocacy. Given the limited resourcing in many ancillary funds (most of which have no paid staff) (Williamson et al. 2017), managers' and trustees' roles often overlapped in practice, and several participants described their roles as encompassing both functions.

Elite interviews are those with people at the top of their hierarchy, such as organisation CEOs, or the very wealthy (Harvey 2011). The PAF managers and trustees who participated in this study were influential people within their communities, in part due to their roles in grantmaking. Issues particular to elite interviews are access challenges, often shorter timeframes, and interviewees taking control of the discussion: "You let the interviewee decide what to tell you, then sit back and listen" (Rubin and Rubin 2012, 175).

University ethics approval was gained prior to commencing data collection, and a low-risk human ethics consent form was reviewed and signed by participants before each interview commenced. Both individuals and organisations participating were assured of confidentiality.

All interviews were audio-recorded. Interviews were transcribed and data were thematically coded using NVivo software (Paulus et al. 2017). Analysis of the interview transcripts facilitated identification of patterns and themes, similarities and differences across multiple PAFs. The focus of participants' narratives provided an important platform for the exploration and analysis of agenda-setting in these private foundations.

The participating foundations' online public profiles were analysed at the time of the interviews and then reexamined five years following by searching for PAFs websites and any media commentary, observing potential changes in the ways in which their public presence and the information they make available suggests or states an engagement with public policy, advocacy and/or agenda-setting. This provided interesting longitudinal data regarding the public promotion of philanthropy and ways and contexts in which this was being done, recognising emergent changes in public promotion/advocacy of philanthropy.

\section{Findings}

Ways in which agenda-setting was discussed in interviews (with or without using the term itself) included: support, development, influence, direction, best practice, pilot project/program, and convening. Four main themes were identified in the findings: PAFs' agendas, PAFs' advocacy and influence on public policy, advocacy for more philanthropy, and approaches to agenda-setting. Each of these themes is considered below.

\subsection{PAFs' Agendas}

The unique vision and mission of PAFs were described by participants as being part of their agenda-setting. Interestingly, this was not expressed in terms of cause areas but rather approaches to support. One respondent talked about responsiveness or 'seeing opportunities'.

... we certainly just didn't want to hand out cheques to charities ... I wanted the foundation to really be a catalyst for making an impact in whatever way we saw the opportunity (Trustee, PAF 3).

That still remains the vision of the foundation - that it was about really supporting grassroots organisations that other foundations wouldn't support (Manager, PAF 4).

We're happy to invest in people and systems, plant and equipment. We're not keen on doing marketing campaigns (Trustee, PAF 6).

One respondent noted that all foundations have the same over-arching agenda of public benefit but have different foci and approaches.

... there's now another tier of people who are generating those levels of wealth and also realising that yes, there are opportunities to maximise [impact] ... . part of the reason people do this [establish PAFs] is they actually do want to make things better, and the political spectrum is that there are always going to be different ways, beliefs on how you can do that better (Trustee, PAF 7). 
A preference for privacy and the individual leadership styles of PAF founders also contributed to an agenda of quiet philanthropy.

[The founder's] philosophy is quiet leadership ... however I think we might be coming around to the point, and this is my personal opinion, that we need a more vocal leadership, but it won't be standing on a soapbox (Manager, PAF 8).

There has been a lot of talk at a board level around a public face for the foundation and recognising that as the foundation grows and becomes one of the biggest foundations here in [name of state] that we have a role to play ... but at the moment private means just that - it's very private (Manager, PAF 10).

\subsection{PAF Advocacy and Influence on Public Policy}

None of the interviewees noted actions of overtly attempting to change government policy. Respondents perceived that most in the population of PAFs were not interested in systemic change and were a long distance from engaging with public policy. Public impact was hindered by privateness as it limited foundations' ability to receive feedback and influence a public agenda. " ... if we don't tell the world what we're doing, (a) how can we encourage other people to establish their own charity giving, or (b) know about where the needs are?" (Trustee, PAF 6). However, they felt a responsibility to address and communicate existing social needs and influence others' philanthropic giving.

These are families - these are mums and dads - there are a whole variety of reasons why they've established one [a PAF] but ... they're a long way from ever thinking about policy, and may never get there (Manager, PAF 10).

The same respondent observed, "I could count on one hand the number that would be really genuinely interested in systemic government change" (Manager, PAF 10).

Founders may get to a level of experience and expertise where they begin to think about policy as a means of effecting change, but this almost always took years of involvement in philanthropy to achieve.

I can think of one [PAF] off the top of my head that started from day one saying, "This is what we're going to do. This is how we're going to do it. This is how we're going to change things." The rest of them? It takes three to five years ... (Manager, PAF 10).

PAFs noted examples of alignment with government policy and programs, but also instances of change or disconnect.

The government has actually got a blueprint on changing the culture of the state ... what I'm doing with these programs is I'm changing the wellbeing of children ... Funnily enough, what that's about is actually fitting into what the state wants to do (Trustee, PAF 3).

... a government institution ${ }^{3}$ we were involved in who decided then to cancel it [a project] just out of the blue and didn't tell us about it. I was about to write a cheque for the next year's payment so we were a bit stunned ... [we are questioning] whether we from now on get involved in government institutions ... well governments full stop, because they have a definite agenda (Trustee, PAF 6).

\subsection{Advocacy for More Philanthropy}

Agenda-setting or framing was discussed primarily in terms of the philanthropic sector itself, where respondents were advocates for establishing PAFs. "... we host and co-convene something called the [name] meeting in the hope that will bring other philanthropists to the table" (Manager, PAF 8). This was often done through in-person networks and at events. " ... being advocates and telling our story at those [nonprofit sector] events is a contribution to the community (Trustee, PAF 9).

... there is a very strong core of people who have them [PAFs] who are really working to promote that they exist, that you too could set one up, that it's a great way to engage with the family. They're advocates for doing it ... philanthropy does tend to be more quiet and private. So the shift to talking about it more and being more open about it and having media stories done has been gradually changing (Manager, PAF 1). 
Thus PAFs' informal agendas were often about promoting structured philanthropy, in addition to pursuing their formal agenda of the individual purposes for which they were established.

I'm hoping to draw people into the world of philanthropy in the same way I was drawn into it and philanthropy takes all forms ... So if I can stand up there and say, "I have a foundation", that in itself sends a message ... I think a lot of people need to be led into this area (Trustee, PAF 3).

I'm often pushing them to be more outspoken about what they do because I really do see them leading the way for a lot of other PAFs (Manager, PAF 4).

... demonstrating leadership. In fact, our first social investment was about just that. It's a social investment but it's also about making a statement to other philanthropists that these things should be contemplated and indeed done wherever possible (Manager, PAF 8).

\subsection{Approaches to Agenda-Setting}

One foundation observed that their grantmaking role gave them a valuable overview and perspective on nonprofit activity in their interest areas. "These PAFs do get a bit of a bird's eye view that perhaps other people or other organisations don't" (Manager, PAF 4). This sometimes led to agenda-setting through introducing nonprofit beneficiaries to other funders. Another form of advocacy was co-funding and collaborative support by a pair or small group of PAFs with a shared frame of interest. " ... these three PAFs, I know that they're all interested and they're all mates, they might like to support it together" (Manager, PAF 4). This was done for the benefit of both funders and beneficiaries interested in similar issues.

... we've done it a few times in supporting a couple of [issue] programs which also affects decisionmaking because now we know that there are two [nonprofits] doing the same thing (Manager, PAF 4).

I have an organisation that we give considerable funds to and ... I try and introduce them to other funders. So some we work really, really closely with and other ones we try and introduce other funders to (Manager, PAF 8).

One respondent identified benefits of collaborative funding as including increased power to create impact through working together.

... [collaborative funding] lessens the risk if you can get other funders on board and it's got the potential to raise more money. I think there's power with a group of people ... I think other trusts and foundations like it as well (Manager, PAF 5).

Agenda-setting was also achieved through personal influence, purposefully used to achieve identified goals regarding individual social change agendas.

It's a bit of a personality thing, isn't it? [The founder] is one of those people who ... he sees that he can influence the people around him in positive ways ... He is an influencer - ripples out the water. So I think he will see that ... to maximise the bang for buck you can also increase those ripples in your own spheres of influence in the community (Trustee, PAF 7).

The same respondent discussed philanthropists as a group of people with different qualities and expertise from those working in the charitable sector, in terms of their ability to achieve leverage and influence for social causes.

... that's the beauty I think of PAFs as well because that's the skill of a lot of these people. They know how to maximise their influence in the corporate world. So you take those people and you apply them in the charitable sector - amazing [results]. Working with people who are genuinely good people or have skills in other ways but maybe they don't have the skill in the maximising influence in the way corporate people do, so you put the two together (Trustee, PAF 7).

\subsection{Changes Over Time In Public Engagement and Advocacy}

In 2014, only two of the 10 participating PAFs (8 and 5) had websites or webpages, which provided detail regarding their philanthropic mission, but did not indicate activity relating to public policy, agenda-setting, or 
advocacy. Further, all 10 PAFs indicated valuing their privacy, rather than having a strong and visible public presence. A review of the PAF's publicly available data five years later revealed two additional PAFs (6 and 10) had created websites in the time between interviews in 2014, and a further four (PAFs 1,3,4 and 9) had profiles on the websites of other philanthropic organisations. Thus only two PAFs continued to have no online presence at all.

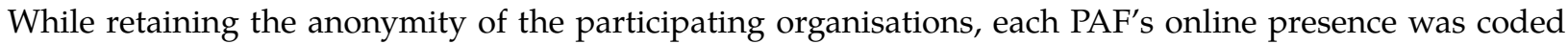
as illustrating advocacy or agenda-setting for either or both philanthropy itself, or a cause area or issue. To be coded for advocacy or agenda-setting required details of activities and commitments beyond grantmaking. Of the eight PAFs with an online presence, four were identified as engaging in advocacy for philanthropy, and of these four, two were additionally identified as engaging in advocacy for a particular cause or issue. Four were identified as not engaging in advocacy at all. None of the online disclosure extended to influencing public policy.

\section{Discussion, Conclusions and Contributions}

Public policy is improved through the work and contribution of charities (including foundations) on important social and cultural issues (Leat 2016). The unique and complementary voice of the nonprofit sector facilitates the development of more robust and more effective public policy. Grantmaking foundations such as PAFs cannot deliver services, so engaging with public policy is potentially an additional string to their bow. Yet "engaging in advocacy or overt pursuit of policy changes has been difficult territory for [Australian] philanthropic foundations, where it is perceived that their charitable status would be at risk, although this is often a misperception" (McGregor-Lowndes and Williamson 2018, 1772).

The balance between whether foundations react to or drive social movements is subject to ongoing scrutiny in the literature and public discourses; with large foundations often highlighted for their catalytic roles (Leat 2016; Fleishman 2007), and positional reputations. Understandings of foundations' advocacy thus tend to be based on very public positions of a select few foundations. However, based on this study's findings, this perception is not reflective of the PAFs interviewed, nor their understanding of the wider PAF population. "The roles claimed by Australian foundations for their work are known only through their publicly available statements, particularly those on the websites of foundations that choose to have a public presence. The information is therefore strongly biased in favour of those foundations that perceive their role to involve community and public engagement, in which an element of advocacy is implicit" (McGregor-Lowndes and Williamson 2018, 1773).

Instead, findings suggest PAFs' agendas are largely consistent with public policy but may vary in their approaches to address social causes. Further, a preference for privacy indicates the PAF sector may be characterised as 'quiet philanthropy' rather than having a visible public presence. With respect to advocacy and agenda-setting, findings highlight advocacy of philanthropy through scaling up and encouraging others to become involved in structured giving and in philanthropy generally, rather than supporting specific social causes. This may be attributable to a relatively young sector as well as the Australian regulatory and cultural context (Murray 2019).

Gitlin's (1980) 'little tacit theories' about what happens and matters is a good description of agenda-setting in PAFs. Agendas and frames represent persistent patterns of presentation and emphasis but are not deliberate policy positions. What actually goes on is more subtle, and the impact of this agenda-setting goes largely unnoticed and underestimated. This simplicity may be deceptive, and this study goes some way towards making evident these small, incremental forms of agenda-setting and framing undertaken by private foundations. Overshadowed by the higher profile cultivated by those foundations with an overt advocacy mission, the quieter, more ad-hoc and sometimes unplanned work of private foundations around agenda-setting and issue framing is an important addition to the literature on nonprofit organisations. Privateness works against public impact, hindering feedback cycles and broader agenda-setting. On the other hand, collaborations and co-funding between small groups of private foundations may lead to greater influence, as can individual founders' personal qualities and values.

A contribution from the study is the recurring theme of advocacy by PAFs for philanthropy in general and more PAFs in particular. This was the most common subject for advocacy by respondents, and a strong shared link between the foundations interviewed. This is perhaps unsurprising in that their identity as philanthropic foundations is shared, whereas their interest areas are not.

Our research finds interest in the tentative and the quiet within structured philanthropic giving. That the Australian context may in international comparisons appear benign and seemingly avoid contention underscores the value of our findings in the 'middle-ground' of philanthropy. This study adds to empirical research 
on the agenda-setting roles played by smaller, private foundations. The issue of foundations focusing on ameliorative work rather than structural change work references the distinction between charity, characterised as ameliorative and short-term, and philanthropy characterised as preventative and longer-term (Daly 2012). Changes noted over time were the participating PAFs accepting a more public presence, but largely limiting the scope of their advocacy to the promotion of philanthropy.

This paper has focused on 10 private foundations within an Australian context. Given the small sample size, it is acknowledged that findings cannot be empirically or statistically generalised to the PAF population or to other foundation types, particularly in view of the changing environment for philanthropy and advocacy, both in Australia and internationally. Theoretical insights are instead drawn through exploration and extension. Opportunities are presented to build upon these initial findings within different research settings, larger sample sizes, and varying timeframes. Future research around public policy and philanthropy in Australia could address questions around whether, how, and with what drivers foundations' roles will shift from providing charitable relief to more deliberately and actively attempting to influence policy reform.

\section{Notes}

1 "Based on the English Pemsel notions of public benefiting purposes: relieving poverty, advancing education, religion, and analogous objects as set out in the Charities Act 2013 (Commonwealth)" (McGregor-Lowndes and Williamson 2018, 1769).

2 An exception is the Ramsay Foundation funding the separate Ramsay Centre for Western Civilisation, criticised for its reported desire to control University curricula in studies of Western Civilisation which it in turn seeks to fund.

3 Some government-owned institutions such as art galleries and museums are granted DGR status and are thus eligible recipients of grants from philanthropic foundations.

\section{References}

Acs, Z. 2013. Why Philanthropy Matters: How the Wealthy Give, and What It Means for Our Economic Well-being. Princeton, New Jersey: Princeton University Press.

Advocacy. n.d. In Collins English Thesaurus. https://www.collinsdictionary.com/dictionary/english-thesaurus/advocacy.

Aid/Watch Incorporated v Commissioner of Taxation. 2010. High Court of Australia.

Anheier, H. K., and S. Daly. 2006. "Philanthropic Foundations in Modern Society." In The Politics of Foundations. A Comparative Analysis, edited by Helmut K Anheier, and Siobhan Daly, 3-26. New York: Routledge.

Anheier, H. K., and D. Leat. 2018. Performance Measurement in Philanthropic Foundations: the Ambiguity of Success and Failure. London: Routledge.

Anheier, H. K., and S. Toepler. 1999. Private Funds, Public Purpose: Philanthropic Foundations in International perspective. Nonprofit and Civil Society Studies. New York: Kluwer Academic/Plenum Publishers.

Arnove, R. F. ed. 1982. Philanthropy and Cultural Imperialism: The Foundations at Home and Abroad. Bloomington, IN: Indiana University Press. Australian Taxation Office. 2019. "Private and Public Ancillary Funds, 2000-01 to 2016-17 Income Years." Taxation Statistics 201617. Charities - Table 4 Australian Government, Accessed December 12. https://data.gov.au/data/dataset/taxation-statistics-201617/resource/abdc1c08-eefo-4220-9e6d-2817458f8aea.

Baker, C., J. Barraket, and A. Elmes. 2017. Civing Australia 2016: Philanthropy and Philanthropists. Canberra: Australian Centre for Philanthropy and Nonprofit Studies, QUT; Centre for Social Impact Swinburne, Swinburne University of Technology; Centre for Corporate Public Affairs.

Callahan, D. 2017. The Givers: Wealth, Power, and Philanthropy in a New Gilded Age. New York: Vintage, Knopf Doubleday Publishing Group.

Canada, Philanthropic Foundations. 2017. A Portrait of Canadian Foundation Philanthropy. Montreal: Philanthropic Foundations Canada.

Coates, P. 2019. “Australia's 50 Biggest Civers." Australian Financial Review 2 (May): 2019. https://www.afr.com/wealth/people/australia-s-50biggest-givers-20190329-p518yi.

Commonwealth of Australia. 2013. Charities Act, edited by. Canberra: Parliament of Australia.

Curtis, C., C. Vanstone, and L. Weinstein. 2019. Philanthropy, Systems and Change. Adelaide: Paul Ramsay Foundation, Dusseldorp Forum, Perpetual, The Australian Centre for Social Innovation.

Daly, S. 2012. "Philanthropy as an Essentially Contested Concept." VOLUNTAS: International Journal of Voluntary and Nonprofit Organizations 23 (3): 535-57.

Fack, G., and C. Landais. 2012. Charitable Giving Tax Policy: A Historical Comparative Perspective. Paris: Centre for Economic Policy Research (CEPR) Conference.

Fleishman, J. L. 2007. The Foundation: A Great American Secret; How Private Wealth Is Changing the World. New York: PublicAffairs and Perseus Books Group.

Franklin, J. 2014. Philanthropy \& Policy Change: Exploring the Role of Private Charitable Foundations in the Policymaking Process. Ph.D., New York: New York University (3642618).

Frumkin, P. 2004. “Inside Venture Philanthropy." In In Search of the Nonprofit Sector, edited by Peter Frumkin, and Jonathan B. Imber, 99-114. New York: Routledge.

Cen, S., and A. C. Wright. 2018. "Strategies of Policy Advocacy Organizations and Their Theoretical Affinities: Evidence from QMethodology." Policy Studies Journal 46 (2): 298-326. 
Cibson, C., and ]. Bokoff. 2020. Teaming Up For Advocacy: How To Effectively Use A Collaborative To Drive Change. New York: Candid . Gitlin, T. 1980. The Whole World Is Watching: Mass Media in the Making and Unmaking of the New Left. University of California Press. Goffman, E. 1974. Frame Analysis: an Essay on the Organization of Experience. Cambridge, MA: Harvard University Press.

Graddy, E. A., and D. L. Morgan. 2006. "Community Foundations, Organizational Strategy, and Public Policy." Nonprofit and Voluntary Sector Quarterly 35 (4): 605-30.

Harvey, W. S. 2011. “Strategies for Conducting Elite Interviews.” Qualitative Research 11 (4): 431-41.

Irvin, R. A., and E. Kavvas. 2019. “Mission Change over Time in U.S. Family Foundations.” Nonprofit and Voluntary Sector Quarterly o (0): 0.

Jones, J. A., R. A. Cantrell, and A. B. Lindsey. 2019. "America's Worst Charities: The Effect of Bad Press on Philanthropic Civing Behavior." Nonprofit and Voluntary Sector Marketing 24: 1.

Joyce, C. 2016. “Charity Moves Millions but Advocacy Can Move Billions: McKinnon Family Foundation." In Fundraising \& Philanthropy, edited by Jeremy Bradshaw. Newcastle, Australia: Bombora Publishing.

Jung, T., and J. Harrow. 2015. "Philanthropy in Networked Governance—treading with Care." Public Money \& Management 35 (1): 47-52.

Jung, T., J. Kaufmann, and J. Harrow. 2013. “When Funders Do Direct Advocacy: An Exploration of the United Kingdom's Corston Independent Funders' Coalition." Nonprofit and Voluntary Sector Quarterly 43 (1): 36-56.

Kingdon, J. W., and J. A. Thurber. 1984. Agendas, Alternatives, and Public Policies, vol. 45. Boston: Little, Brown.

Leat, D. 2004. The Development of Community Foundations in Australia: Recreating the American Dream. Brisbane: Australian Centre for Philanthropy and Nonprofit Studies, QUT.

Leat, D. 2016. Philanthropic Foundations, Public Cood and Public Policy. London: Palgrave Macmillan.

Lee, R. 2015. “Charity without Politics? Exploring the Limits of 'Politics' in Charity Law.” Journal of Civil Society 11 (3): 271-82.

Lungeanu, R., and J. L. Ward. 2012. "A Governance-Based Typology of Family Foundations: the Effect of Generation Stage and Governance Structure on Family Philanthropic Activities." Family Business Review 25 (4): 409-24.

McCombs, M. E., and D. L. Shaw. 1972. “The Agenda-Setting Function of Mass Media.” Public Opinion Quarterly 36 (2): $176-87$.

McGregor-Lowndes, M. 2018. Country Report 2018: Australia. Indiana University (IUPUI ScholarWorks).

McGregor-Lowndes, M., and M. Crittall. 2015. Ancillary Funds 2000-2013. Brisbane: QUT.

McGregor-Lowndes, M., and A. Williamson. 2018. "Foundations in Australia: Dimensions for International Comparison." American Behavioral Scientist 62 (13): 1759-76.

McLeod, J. 2013. The PAF Report - Private Ancillary Funds after 12 Years. Melbourne: JBWere Ltd.

McLeod, J. 2018. The Support Report: The Changing Shape of Civing and the Significant Implications for Recipients. Sydney: JBWere Ltd.

Mills, C. 2011. "Framing Literacy Policy: Power and Policy Drivers in Primary Schools." Literacy 45 (3): 103-10.

Murray, I. 2019. "Regulating Charity in a Federated State: The Australian Perspective." Nonprofit Policy Forum 9 (4). https://www.degruyter.com/view/j/npf.2018.9.issue-4/npf-2018-0034/npf-2018-0034.xml.

Muukkonen, M. 2009. "Framing the Field: Civil Society and Related Concepts." Nonprofit and Voluntary Sector Quarterly 38 (4): $684-700$.

Nemon, M. L., C. J. Jacobs, M. Phillips, and ]. Sneath. 2015. “The Family Foundation Life Cycle and the Role of Consultants." The Foundation Review 7 (1): 19-32.

Nisbet, M. C. 2018. “Strategic Philanthropy in the post-Cap-and-Trade Years: Reviewing U.S. Climate and Energy Foundation Funding.” Wiley Interdisciplinary Reviews: Climate Change 9 (4): e524.

O'Halloran, K., and M. McCregor-Lowndes. 2011. "Charity Law, Advocacy and the Aid/Watch Decision: Compatibility of Charitable Purposes and Political Objects — the View from Australia." The Charity Law \& Practice Review 13: 1-25.

Paulus, T., M. Woods, D. P. Atkins, and R. Macklin. 2017. “The Discourse of QDAS: Reporting Practices of ATLAS.ti And NVivo Users with Implications for Best Practices." International Journal of Social Research Methodology 20 (1): 35-47.

Phillips, S. D. 2018. “Dancing with Giraffes: Why Philanthropy Matters for Public Management.” Canadian Public Administration 61 (2): 151-83.

Reich, R. 2018. Just Giving: Why Philanthropy Is Failing Democracy and How It Can Do Better. New Jersey: Princeton University Press.

Roelofs, ]. 2015. "How Foundations Exercise Power." American Journal of Economics and Sociology 74 (4): 654-75.

Rogers, E. M., and J. W. Dearing. 1988. “Agenda-Setting Research: Where Has It Been, Where Is It Coing?” Annals of the International Communication Association 11 (1): 555-94.

Rubin, H. J., and I. S. Rubin. 2012. Qualitative Interviewing: The Art of Hearing Data, 3rd ed. Thousand Oaks, CA: SAGE Publications, Inc.

Scaife, W. 2013. "Of Forrests and Acorns: Philanthropic Gift May Seed Other University Giving." In The Conversation. Melbourne: The Conversation Media Group.

Scaife, W., K. McDonald, A. Williamson, and V. Mossel. 2015. “Civing in Australia: Philanthropic Potential Beginning to Be Realized." In The Palgrave Handbook of Clobal Philanthropy, edited by Pamala Wiepking, and Femida Handy, 488-506. London: Palgrave Macmillan.

Scaife, W., A. Williamson, K. McDonald, and S. Smyllie. 2012. Foundations for Giving: How and Why Australians Structure Their Philanthropy. Brisbane: Australian Centre for Philanthropy and Nonprofit Studies, QUT.

Seibert, K. 2017. “Twiggy Forrest Donation: More Philanthropy Means More Risk-taking - and That's Cood." In The Conversation. Melbourne: The Conversation Media Group.

Seibert, K. 2018. The Power of Advocacy: Making the Case for Philanthropic Support for Advocacy. Melbourne: Philanthropy Australia.

Seibert, K. 2019. "Civing under the Microscope: Philanthropy, Legitimacy and a New Era of Scrutiny." Third Sector Review 25 (1): $123-41$.

Silber, I. F. 2012. "The Angry Gift: A Neglected Facet of Philanthropy." Current Sociology 60 (3): 320-37.

Suárez, D. F. 2012. “Crant Making as Advocacy: the Emergence of Social Justice Philanthropy.” Nonprofit Management and Leadership 22 (3): 259-80.

Ward, D. 2016. Public Ancillary Funds (Puaf) Trustee Handbook, 2nd ed. Melbourne: Philanthropy Australia, Australian Philanthropic Services.

Weissert, C. S., and ]. H. Knott. 1995. “Foundations' Impact On Policy Making: Results From A Pilot Study." Health Affairs 14 (4): $275-86$.

Williamson, A., B. Luke, and C. Furneaux. 2019a. From Opinion to Data: Undertaking Empirical Research in a Controversial Public Policy Context. SACE Research Methods Cases. London: SAGE Publications.

Williamson, A., B. Luke, and C. Furneaux. 2019b. “Privateness, Accountability and Philanthropic Foundations.” Third Sector Review 25 (2): 14776. 
Williamson, A., B. Luke, D. Leat, and C. Furneaux. 2017. “Founders, Families, and Futures: Perspectives on the Accountability of Australian Private Ancillary Funds." Nonprofit and Voluntary Sector Quarterly 46 (4): 747-71. 